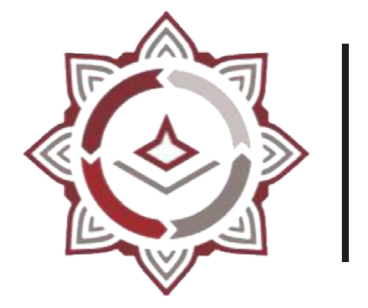

BISNIS: Jurnal Bisnis dan Manajemen Islam

P-ISSN: 2442-3718, E-ISSN: 2477-5533

Volume 9, Nomor 2, Desember 2021 (PP : 193-204)

https://journal.iainkudus.ac.id/index.php/Bisnis/index

http://dx.doi.org/10.21043/bisnis.v9i2.11897

\title{
Pengaruh Leverage dan Profitabilitas terhadap Nilai Perusahaan dengan Islamic Social Reporting (ISR) sebagai Variabel Intervening pada Perusahaan yang Terdaftar di Jakarta Islamic Index (JII) Periode 2016 - 2020
}

\author{
Nurika Rizki Amalia1, Fetria Eka Yudiana² \\ IAIN Salatiga \\ rizkinurika@gmail.com
}

\begin{abstract}
Abstrak
This study aims to determine the effect of Leverage (DER), Profitability (ROA), on Firm Value (PBV) with Islamic Social Reporting (ISR) as an Intervening Variable in Companies Listed in the Jakarta Islamic Index (JII) 2016 - 2020. This study using quantitative data with path analysis test or path analysis as data analysis. Based on the results obtained from the test which shows that the Leverage variable partially has a significant positive effect on Firm Value, Profitability partially has a significant positive effect on Firm Value, Leverage partially has a significant positive effect on ISR, Profitability partially has an insignificant positive effect on ISR, ISR has no significant positive effect on Firm Value, F test results show that together the variables Leverage, Profitability and Islamic Social Reporting (ISR) have a significant effect on Firm Value. While the results of path analysis or path analysis show that the Islamic Social Reporting (ISR) variable is ableto mediate the influence of Leverage on firm value. However, it cannot mediate the effect ofprofitability on firm value.
\end{abstract}

Keywords: Leverage (DER), Profitability (ROA), Firm Value (PBV), Islamic Social Reporting (ISR)

\begin{abstract}
Abstrak
Penelitian ini mempunyai tujuan untuk mengetahui pengaruh Leverage (DER), Profitabilitas (ROA), terhadap Nilai Perusahaan (PBV) dengan Islamic Social Reporting (ISR) sebagai Variabel Intervening pada Perusahaan yang Tercatat di Jakarta Islamic Index (JII) Periode 2016 - 2020. Penelitian ini menggunakan data kuantitatif dengan uji analisis jalur atau path analysis sebagai analisis data. Berdasarkan hasil penelitian diperoleh hasil uji t yang menunjukkan bahwa variabel Leverage secara parsial berpengaruh positif signifikan
\end{abstract}


terhadap Nilai Perusahaan, Profitabilitas secara parsial berpengaruh positif signifikan terhadap Nilai Perusahaan, Leverage secara parsial berpengaruh positif signifikan terhadap ISR, Profitabilitas secara parsial berpengaruh positif tidak signifikan terhadap ISR, ISR berpengaruh positif tidak signifikan terhadap Nilai Perusahaan, Hasil Uji F menunjukan bahwa secara bersama-sama variabel Leverage, Profitabilitas dan Islamic Social Reporting (ISR) berpengaruh signifikan terhadap Nilai Perusahaan. Sedangkan hasil analisis jalur atau path analysis menunjukkan bahwa variabel Islamic Social Reporting (ISR) mampu memediasi pengaruh Leverage terhadap nilai perusahaan. Namun tidak dapat memediasi pengaruh Profitabilitas terhadap nilai perusahaan.

Kata Kunci: Leverage (DER), Profitabilitas (ROA), Nilai Perusahaan (PBV), Islamic Social Reporting (ISR)

\section{PENDAHULUAN}

Pertumbuhan ekonomi dan bisnis akhir-akhir ini membuat para investor, pebisnis, dan juga sumber daya manusia dalam sebuah perusahaan harus dapat menyesuaikan perkembangan tersebut. Dalam menghadapi sebuah tantangan seperti krisis keuangan global sebuah perusahaan serta sumber dayanya harus bisa menyesuaikan diri agar dapat bersaing dalam bisnis yang kini kian ketat. Oleh karena itu sumber daya manusia harus bisa kompeten dalam menjalankan perusahaan. Perkembangan pasar harus dapat di manajemen dengan cara menganalisa dan membacanya sehingga dapat menemukan cara yang tepat dalam mempertahankan kelangsungan bisnis. Tujuan dari perusahaan berupa jangka panjang serta tujuan jangka pendek. Tujuan jangka pendeknya yaitumendapatkan laba secara maksimum melalui kepemilikan sumbar dayanya, sementara tujuan jangka panjangnya ialah meningkatkan kesejahteraan pemegang saham atau pemilik perusahaan. Hal tersebut karena makin besar nilai perusahaan artinya semakin tinggi tingkat kemakmuran perusahaan tersebut.

Sejumlah harta yang akan dibayarkan ditanggung calon customer perusahaan saat perusahaan tesebut akan dijual adalah pengertian nilai perusahaan. Pada penelitian ini proksi yang digunakan adalah Price to Book Value(PBV) di variabel nilai perusahaan. Harapan perusahaan ialah mendapatkan nilaiperusahaan yang tinggi, karena smakin tingi nilai perusahaan artinya semakin makmur pula para investor. Istilah lain nilai perusahaan dapat diartikan dengan nilai pasar karena dapat memberi informasi kepada pemegang saham tentang kesuksesan perusahaan ketika harga saham perusahaan meningkat. Tingginya nilai saham dalam perusahaan tersebut artinya semakin tinggi nilai perusahaan, hal ini dapat mempengaruhi penanam modal agar menanamkan modalnya dalamperusahaan tersebut. 
Nilai perusahaan bisa menjadi cerminan nilai asset milik perusahaan contohnya surat berharga yang antara lain ialah saham. Saham adalah baguan dari surat berharga yang dimiliki perusahaan dan dipublikasikan oleh perusahaan. Dalam jual beli saham di pasar modal harus memperhatikan perubahan harga saham karena hal ini dinilai perlu serta wajib dicermati oleh pembeli atau investor ketika akan berinvestasi.

Leverage adalah kekuatan sebuah perusahaan untuk melaksanakan kewajiban keuangan jangka pendek ataupun jangka panjangnya ketika perusahaan tersebut mengalamilikuidasi(Prakosa,2017).Artinyakemampuan perusahaan untukmembayar hutangnya dihitung menggunakan Leverage Menurut Kasmir, (2016) Solvabilitas menurutnya merupakan rasio pengukuran aktiva perusahaan yang dibiayai dengan utang. Menurut Desriana, (2017) sebuah perusahaan yang solvable dapat diartikan bahwa perusahaan tersebut dapat membayar semua hutangnya dengan aktiva yang dimiliki atau perusahaan tersebut likuid. Dari asumsi tersebut dapat dikatakan bahwa keterkaitan antara profitabilitas dan solvabilitas yaitu negatif. Indikator dari laverage yaitu Dept to Equity Ratio (DER) yang juga diproksikan dalam penelitian ini.

Menurut Saputra, (2019) rasio profitabilitas akan menjadi alat untuk mengukur mampu tidaknya perusahaan dalam mendapatkan laba. Profitabilitas adalah kesanggupan perusahaan dalam mendapatkan keuntungan perusahaan atau sebuah pengukuran efektivitas penanganan perusahaan dalam mengurus manjemennya (Prakosa, 2017). Hubungan antara profitabilitas dengan nilai perusahaan bisa dikatakan berhubungan positif atau berbanding lurus, hal tersebut menunjukan kinerja sebuah perusahaan. Profitabilitas bisa diukur melalu Return Of Asset (ROA) melalui cara membagikan laba bersih setelah pajakdengan total asset. Apabila ROA meningkat bagian keuntungan hak pemilik modaljuga akan meningkat.

Terdapatunsurlainyang berdampakpada nilai perusahaanyaitu CorporateSocial Responsibility (CSR). Banyak perusahaan telah menggunakan CSR sebagai straregi bisnis. Di dalam prinsip syariah islam terdapat cara dalam menilai pengungkapan sosial suatu perusahaan menggunakan indeks Islamic Social Reporting (ISR) yang berisikan laporan pengungkapan sosial perusahaan secara umum berdasarkan prinsip-prinsip syariah islam melalui laporan tahunan. Islamic Social Reporting dinilai penting bagi perusahaan karena mampu mewujudkan transparansi perusahaan yang bisa memberikan kepercayaan dan juga meningkatnya nilai perusahaan.

Berdasarkan penelitian terdahulu yang dilakukan oleh Ayuni, 2020 tentang Pengaruh Leverage, Kinerja Keuangan dan Profitabilitas terhadap Nilai Perusahaan dengan ISR sebagai Variabel Intervening (Studi Pada Bank Umum Syariah Periode 
2014-2018) memiliki kesimpulan bahwa secara parsial tidak ada variabel yang berpengaruh terhadap nilai perusahaan kecuali variabel Islamic Social Reporting (ISR). Sedangkan secara simultan keseluruhan variabel berpengaruh terhadap Nilai Perusahaan. Sedangkan hasil path analysis menunjukkan bahwa variabel ISR dapat memediasi pengaruh Leverage dan Profitabilitas terhadap Nilai Perusahaan, namun tidak dapat memediasi pengaruhKinerja Keuangan terhadap Nilai Perusahaan.

Berdasarkan penelitian yang sebelumnya, diperoleh research gap yang menimbulkan peneliti melakukan penelitian ini. Beberapa tujuan penelitian ini antara lain mengetahui pengaruh variabel independen (Leverage dan profitabilitas) terhadap nilai perusahaan dan Islamic Social Reporting (ISR), mengetahui pengaruh Islamic Social Reporting terhadap nilai perusahaan, dan mengetahui pengaruh Islamic Social Reporting dalam memediasi hubungan antara Leverage dan profitabilitas dengan nilai perusahaan pada perusahaan yangtercatat di Jakarta Islamic Index (JII) periode 2016 - 2020

\section{KAJIAN LITERATUR}

\section{Signalling Theory}

Signalling Theory merupakan teori yang mengungkapkan terkait naik turun harga di pasar yang kemudian bisa berpengaruh terhadap keputusan investor. Teori ini pertama kali ditemukan dalam karya tulisan George Akerlof dengan judulnya "The Market for Lemons" di tahun 1970. Keputusan para investor terkaitinformasi positif dan negatif sangat berpengaruh terhadap kondisi pasar. Para pemegang saham akan menanggapi melalui berbagai cara, seperti membeli saham yang akan dijual ataupun melakukan sebuah tindakan berupa tunggu dan lihat atau biasa disebut dengan istilah "wait and see" terlebih dahulu kemudian akan menngambil keputusan. Keputusan ini bukanlah keputusan yang kurang bagus atau salah, melainkan hal tersebut merupakan bentuk tindakan para pemegang saham dalam mencegah risiko yang disebabkan oleh faktor pasar yang belum bisa memberikan keuntungan ataupun pihaknya (Handini, 2020).

\section{Stakeholder Theory}

Stakeholder Theory menggambarkan bahwa perusahan tidak akan mengoperasikan kegiatanya hanya dalam rangka kepentingan mandiri namun juga bermanfaat bagi stakeholder-nya. Dalam artian dukungan stakeholder dapat 
mempengaruhi keberadaan perusahaan (Budiasni \& Darma, 2020). Teori ini berisi tentang cara manajemen perusahaan dalam memenuhi keinginan stakeholder. Sebuah peusahaan akan mendapatkan hasil yang maksimal apabila mendapatkan dukungan dari stakeholder. CSR adalah salah satu strategi yang digunakan perusahaan dalam memenuhi keinginan stakeholder dalam informasi yang tidak berhubungan dengan keuangan namun berhubungan dengan lingkungan sosial serta dampak yang terjadi akibat kegiatan perusahaan. Selama CSR diungkapkan dengan baik maka stakeholder mampu memberikan semangat dukunganya agar kinerja perusahaan bisa meningkat dan memperoleh pendapatan yang ditargetkan (Susanti, 2019).

\section{Nilai Perusahaan}

Nilai perusahaan menjelaskan akuisisi serta nilai perdaganggan perusahaan yang diantisipasi oleh pembeli serta penjual berisi semua informasi perusahaan yang terbebas dalam masalah (Gurelyuz, 2009 dalam Samidi, 2021). Dengan kata lain pembayaran yang akan dilakukan oleh calon customer berupa harga ketika perusahaan tersebut dipindah tangankan kepada pihak lain. Ketika nilai perusahaan tinggi maka akan mengakibatkan keinginan untuk memiliki perusahaan tersebut semaki banyak, karena ketika nilai perusahaan tinggi akan menunjukan kesejahteraan bagi investor. Kekayaan sebuah perusahaan dan investor diuraikan oleh harga pasaran saham yang berupa gambaran atas keputusan investasi, pembiayaan, serta manajemen asset. Ketika ada peluang investasi dalam sebuah perusahaan maka akan memunculkan gelombang positif terkait perkembangan perusahaan di waktu berikutnya dan bisa menumbuhkan nilai perusahaan. Ketika harga saham perusahaan meningkat itu artinya tingkat return kepada investor juga akan tinggi, artinya semakin tinggi pula nilai perusahaan, karena tujuan dari sebuah perusahaan antara lain memaksimalkan kemakmuran investor. Price to Book Value (PVB) merupakan suatu indikator atau rasio untuk menghitung nilai perusahaan. Rasio PVB akan menghitung nilai yang bersumber dari financial market ke manajemen serta organisasi perusahaan yang akan terus berkembang (Brigham \& Houston, 2015).

\section{Leverage}

Leverage atau rasio solvabilitas disebut juga rasio yang mencerminkan kekuatan sebuah perusahaan dalam mmenuhi kewajiban-kewajiban finansial entah jangka pendek ataupun jangka panjang (Hery, 2016). Sedangkan menurut (Brigham, E., \& Houston, 2011) rasio solvabilitas digunakan untuk menggukur sejauh mana 
suatu perusahaan menggunakan hutang. Menurut (Kasmir, 2016), solvabilitas merupakan rasio pengukuraan seberapa jauh aktiva perusahaan ditanggung dari hutang. Dalam artian seberapa banyak beban hutang perusahaan jika disbanding dengan aktivanya. Perusahaan dapat diartikan tidak solvabel apabila perusahaan tersebut mempunyai hutang dengan total yang melebihi total assetnya. Analisis struktur modal adalah salah satu elemen kunci dalam solvabilitas.

\section{Profitabilitas}

Menurut (Kasmir, 2016) rasio profitabilitas disebut juga rasio dalam menilai seberapa besar kekuatan perusahaan untuk memperoleh laba. Dalam kata lain profitabilitas adalah salah satu rasio yang memperlihatkan kombimasi antara pengaruh likuiditas, manajemen aset, serta utang dari pengoperasian atau rasio yang memperlihatkan hasil seluruh kebijakkan keuangan serta keputusan operasional.

\section{Islamic Social Reporting (ISR)}

ISR adalah pengungkapan sosial perusahaan sesuai standar syariah islam, yaitu standar yang digunakan perusahaan dalam menjalankan bisnisnya yang sesuai dengan prinsip dalam islam melalui laporan keuangan (Susanti, 2019). ISR memiliki tujuan untuk menambah transparansi kegiatan bisnis melalui cara menyediakan informasi untuk menambah keperluan spiritual pengguna muslim dalam laporan perusahaan (Cahya, 2017). ISR diterbitkan oleh Accounting and Auditing Organization For Islamic Financial Institution atau AAOIFI.

\section{METODE PENELITIAN}

Penyusunan metode penelitian mengunakan kuantitatif. Penelitian kuantitatif ini mengunakan data yang bersumber dari annual report perusahaan yang tercatat di Jakarta Islamic Index (JII) Periode 2016 - 2020. Penggunaan populasi pada penelitian ini yakni perusahaan yang tercatat di Jakarta Islamic Index (JII) Periode 2016 - 2020. Total ada 30 perusahaan yang tercatat dalam Jakarta Islamic Index (JII). Perusahaan tersebut terpilih dan masuk kedalam JII berdasarkan syarat dan kriteria yang sudah diatur oleh Dewan Pengawas Syariah.Purposive sampling diambil sebagai teknik pengambilan sampel dalam penelitianini. Perusahaan yang dijadikan sampel yaitu perusahaan yang listing di Jakarta Islamic Index (JII) Periode 2016 2020. Berdasarkan teknik pengambilan sampeldihasilkan jumlah sampel sebanyak 
13 perusahaan. Pada metode ini data digabungkan dengann metode dokumentasi atau studi pustaka. Ini merupakan salah satu cara dalam mencari data terkait variabel berupa laporan keuangan yang sudah terpublikasi oleh perusahaan dari tahun 2016 hingga 2020 melalui laman resmi perusahaan dan www.idx.co.id terkait objek penelitian.

\title{
PEMBAHASAN
}

Tabel 1

Uji Regresi Variabel Utama

\author{
Dependent Variable: $Y$ \\ Method: Panel EGLS (Cross-section random effects) \\ Date: 09/04/21 Time: 08:21 \\ Sample: 20162020 \\ Periods included: 5 \\ Cross-sections included: 13 \\ Total panel (balanced) observations: 65 \\ Swamy and Arora estimator of component variances
}

\begin{tabular}{|c|c|c|c|c|}
\hline Variable & Coefficient & Std. Error & t-Statistic & Prob. \\
\hline $\mathrm{C}$ & 11254.14 & 14233.50 & 0.790680 & 0.0321 \\
\hline $\mathrm{X} 1$ & 7051.233 & 3503.670 & 2.012528 & 0.0486 \\
\hline $\mathrm{X} 2$ & 67416.81 & 30716.06 & 2.194839 & 0.0320 \\
\hline Z & 411.8758 & 473.3096 & -0.870204 & 0.3876 \\
\hline \multicolumn{5}{|c|}{ Effects Specification } \\
\hline & & & S.D. & Rho \\
\hline Cross-section random & & & 17793.39 & 0.8738 \\
\hline Idiosyncratic random & & & 6761.356 & 0.1262 \\
\hline \multicolumn{5}{|c|}{ Weighted Statistics } \\
\hline R-squared & 0.975046 & \multirow{2}{*}{\multicolumn{2}{|c|}{$\begin{array}{l}\text { Mean dependentyar } \\
\text { S.D. dependent var }\end{array}$}} & 2307.070 \\
\hline Adjusted R-squared & 0.531196 & & & 7204.092 \\
\hline S.E. of regression & 7010.142 & \multicolumn{2}{|c|}{ Sum squared resid } & $3.00 E+09$ \\
\hline F-statistic & 2.196791 & \multicolumn{2}{|c|}{ Durbin-Watson stat } & 1.916863 \\
\hline Prob(F-statistic) & 0.097524 & & & \\
\hline
\end{tabular}

Sumber: Output Eviews 12 diolah, 2021 
Berdasarkan uji dalam tabel 1 diperoleh Adjusted $\mathrm{R}^{2}$ sebesar 0.975 itu artinya sebesar 97.5\% variabel dependen di pengaruhi oleh variabel independen. Kemudian sisa $2.5 \%$ dipengaruhi oleh variabel yang lain diluar model. Kemudian nilai Prob (F-statistic) sebesar $0.032<0.05$ sehingga kesimpulannya adalah semua variabel $\mathrm{X}$ berpengaruh signifikan terhadap Y. Berdasarkan uji t didapatkan kesimpulan sebagai berikut:

\section{a) Leverage}

Sesuai output uji diatas didapatkan nilai probability 0.048 atau $<0.05$ sehingga kesimpulanya bahwa secara parsial Leverage berpengaruh positif dan signifikan terhadap Nilai Perusahaan

b) Profitabilitas

Berdasarkan hasil uji diatas didapatkan nilai probability 0.032 atau < 0.05sehingga kesimpulanya bahwa secara parsial profitabilitas berpengaruh positif dan signifikan terhadap nilai perusahaan.

\section{c) Islamic Social Reporting}

Berdasarkan hasil uji diatas didapatkan nilai probability 0.387 atau > 0.05maka dapat kesimpulanya bahwa secara parsial Islamic Social Reporting (ISR) bepengaruh positif dan tidak signifikan terhadap nilai perusahaan.

Tabel 2

\section{Regresi Variabel Intervening}

Dependent Variable: $\mathrm{Z}$

Method: Panel Least Squares

Date: 08/19/21 Time: 12:04

Sample: 20162020

Periods included: 5

Cross-sections included: 13

Total panel (balanced) observations: 65 


\begin{tabular}{lrlll}
\hline \hline \multicolumn{1}{c}{ Variable } & Coefficient & Std. Error & t-Statistic & Prob. \\
\hline C & 25.47120 & 2.158030 & 11.80299 & 0.0000 \\
\multicolumn{1}{c}{ X2 } & 1.459096 & 1.279134 & 1.140691 & 0.2594 \\
& 4.119593 & 11.77319 & 0.349913 & 0.7279 \\
\hline \hline & Effects Specification & \\
\hline Cross-section fixed (dummy variables) & & \\
\hline \hline & & & \\
R-squared & 0.675730 & Mean dependent var & 27.23077 \\
Adjusted R-squared & 0.584934 & S.D. dependent var & 3.055575 \\
S.E. of regression & 1.968573 & Akaike info criterion & 4.391669 \\
Sum squared resid & 193.7639 & Schwarz criterion & 4.893451 \\
Log likelihood & -127.7292 & Hannan-Quinn criter. & 4.589654 \\
F-statistic & 7.442313 & Durbin-Watson stat & 1.852829 \\
Prob(F-statistic) & 0.000000 & & \\
\hline \hline
\end{tabular}

Sumber: Output Eviews 12 diolah, 2021

Berdasarkan uji dalam tabel 2 diperoleh Adjusted $R^{2}$ sebesar 0.691 yang artinya sebesar 69.1\% variabel dependen di pengaruhi oleh variabel independen. Kemudian sisa 30.9\% dipengaruhi oleh variabel lainnya diluar model. Kemudian nilai Prob (F-statistic) sebesar $0.000<0.05$ maka kesimpulannya semua variabel

X berpengaruh signifikan terhadap Z. Berdasarkan uji t didapatkan kesimpulansebagai berikut:

a) Leverage

Berdasarkan hasil uji diatas didapatkan nilai probability 0.023 atau < 0.05 artinya bahwa secara parsial Leverage berpengaruh positif signifikan terhadap ISR.

b) Profitabilitas

Berdasarkan hasil uji diatas didapatkan nilai probability 0.931 atau $>0.05$ maka kesimpulanya secara parsial profitabilitas berpengaruh positif dan tidak signifikan terhadap ISR. 
Tabel 3 Analisis Jalur

\begin{tabular}{lcccccc}
\hline Variabel & $\begin{array}{c}\text { Xke } \\
\text { (p1) }\end{array}$ & $\begin{array}{c}\text { Xke Z } \\
\text { (p2) }\end{array}$ & Sp2 & Sp3 & $\begin{array}{c}\text { Pengaruh } \\
\text { Tidak } \\
\text { Langsung }\end{array}$ & Total Efek \\
\hline $\mathrm{X} 1$ & 7051.233 & 1.175 & 3503.670 & 0.751 & 8285.198 & 3504.421 \\
\hline $\mathrm{X} 2$ & 67416.81 & 0.549 & 30716.06 & 6.394 & $37,011.828$ & $30,722.454$ \\
\hline Z ke Y & & & & & & \\
(p3) & 411.875 & & 473.309 & & & \\
\hline
\end{tabular}

Sumber: Data Diolah Dengan Excel, 2021

Berdasarkan tabel diatas diperoleh nilai t hitung pengaruh mediasi sebesar $\mathrm{t} 1=183.942$ dan $\mathrm{t} 2=1.151$. Setelah menghitung nilai $\mathrm{t}$ hitung, berikutnya mencariangka t tabel menggunakan rumus sebagai berikut:

$\begin{aligned} \mathrm{df} & =\mathrm{n}-\mathrm{k} \\ \mathrm{df} & =65-4 \\ \mathrm{df} & =61\end{aligned}$

Berdasarkan perhitungan diatas ditemukan nilai df sebesar 61 dengannilai signifikasi 5\% atau 0.05, maka hasil nilai t tabel sebesar 1.99962.

Setelah melakukan beberapa uji diatas, selanjutnya maka diperoleh kesimpulan dibawah ini:

1. Perhitungan t1 sebesar 183.942 atau $>0.05$ dan lebih besar dari nilai $\mathrm{t}$ tabel 1.6702. Maka dikatakan signifikan dan variabel ISR mampu memediasi dalam pengaruh Leverage dengan nilai perusahaan.

2. Perhitungan $\mathrm{t} 2$ sebesar 1.151 atau $>0.05$ dan lebih kecil dari nilai t tabel 1.6702. Maka dikatakan tidak dan variabel ISR tidak mampu memediasi dalam pengaruh profitabilitas dengan nilai perusahaan.

\section{SIMPULAN}

Penelitian ini mendapatkan hasil uji t yang memperlihatkan variabel Leverage secara parsial berpengaruh positif signifikan terhadap Nilai Perusahaan, Profitabilitas secara parsial berpengaruh positif signifikan terhadap Nilai Perusahaan, Leverage secara parsial berpengaruh positif signifikan terhadap ISR, Profitabilitas secara 
parsial berpengaruh positif tidak signifikan terhadap ISR. Hasil Uji F menunjukan bahwa secara keseluruhan variabel Leverage, Profitabilitas dan Islamic Social Reporting (ISR) berpengaruh signifikan terhadapNilai Perusahaan. Sedangkan hasil path analysis memperlihatkan bahwa variabelIslamic Social Reporting (ISR) mampu memediasi pengaruh Leverage terhadap nilai perusahaan. Namun tidak dapat memediasi pengaruh Profitabilitas terhadapnilai perusahaan.

Variabel Leverage dan profitabilitas memiliki peranan yang penting bagi nilai perusahaan, penggunaan hutang dan laba perusahaan yang banyak dapat mengakibatkan nilai perusahaan meningkat yang kemudian akan memancing investor untuk melakukan investasi di perusahaan tersebut. Berbeda pengaruh dengan ISR, variabel Leverage dan profitabilitas berpengaruh positif namun tidak signifikan, artinya meski Leverage dan profitabilitas tinggi perusahaan akan tetap melakukan pengungkapan sosial.

Tabel 4 Hasil Hipotesis

\begin{tabular}{ccll}
\hline No & Hipotesis & \multicolumn{1}{c}{ Keterangan } & \multicolumn{1}{c}{ Hasil } \\
\hline 1 & H1 & $\begin{array}{l}\text { Leverage berpengaruh negatif terhadap Nilai } \\
\text { Perusahaan }\end{array}$ & Ditolak \\
\hline 2 & H2 & $\begin{array}{l}\text { Profitabilitas berpengaruh positif terhadap } \\
\text { Nilai Perusahaan }\end{array}$ & Diterima \\
\hline 3 & H3 & $\begin{array}{l}\text { Leverage berpengaruh negatif terhadap } \\
\text { Islamic Social Reporting }\end{array}$ & Ditolak \\
\hline \hline 4 & H4 & $\begin{array}{l}\text { Profitabilitas berpengaruh positif terhadap } \\
\text { Islamic Social Reporting }\end{array}$ & Ditolak \\
\hline 5 & H5 & $\begin{array}{l}\text { Islamic Social Reporting berpengaruh negatif } \\
\text { terhadap Nilai Perusahaan }\end{array}$ & Ditolak \\
\hline 6 & H6 & $\begin{array}{l}\text { ISR memediasi pengaruh Leverage terhadapnilai } \\
\text { perusahaan }\end{array}$ & Diterima \\
\hline 7 & H7 & $\begin{array}{l}\text { ISR memediasi pengaruh profitabilitas } \\
\text { terhadap nilai perusahaan }\end{array}$ & Ditolak \\
\hline
\end{tabular}




\section{DAFTAR PUSTAKA}

Ayuni, N. (2020). Pengaruh Leverage, Kinerja Keuangan Dan Profitabilitas Terhadap Nilai Perusahaan Dengan Isr Sebagai Variabel Intervening ( Studi Pada Bank Umum Syariah Periode 2014-2018).

Brigham, E., \& Houston, J. (2011). Dasar-Dasar Manajemen Keuangan (A. A. Yulianto (Ed.); 11th Ed.). Salemba Empat.

Brigham, E., \& Houston, J. . (2015). Fundamentals Of Financial Management (Terjemahan). Salemba Empat.

Cahya, B. T. (2017). Islamic Social Report: Ditinjau Dari Aspek Corporate Governance Strength, Media Exposure Dan Karakteristik Perusahaan Berbasis Syariah Di Indonesia Serta Dampaknya Terhadap Nilai Perusahaan.

Desriana, D. (2017). Pengaruh Likuiditas Dan Solvabilita S Terhadap Profitabilitas Pada Pt. Kalbe Farma, Tbk Yang Terdaftar Di Bursa Efek Indonesia.

Hery. (2016). Financial Ratio For Business. Grasindo.

Kasmir. (2016). Pengantar Manajemen Keuangan: Edisi Kedua (1st Ed.). Kencana Prenada Media Group.

Prakosa, R. W. (2017). Pengaruh Likuiditas Dan Solvabilitas Terhadap Profitabilitas Studi Pada Perusahaan Makanan Dan Minuman Yang TerdaftarDi Indeks Saham Syariah Indonesia (Issi) Periode 2012-2016. 2017.

Samidi. (2021). Model Bisnis Dalam Meningkatkan Nilai Perusahaan Badan Usaha Milik Daerah (Bumd). Nem.

Saputra, L. (2019). Analisis Pengaruh Likuiditas, Solvabilitas Dan Aktivitas Terhadap Kinerja Profitabilitas (Studi Pada Perusahaan Perdagangan Sektor Perdagangan Besar Barang Produksi Dan Eceran Yang Terdaftar Di Indeks Saham Syariah Indonesia (Issi) Tahun 2015-2017).

Susanti, R. (2019). L Analisis Pengaruh Profitabilitas Dan Leverage Terhadap Nilai Perusahaan Dengan Pengungkapan Islamic Social Reporting (Isr) Sebagai Variabel Moderating (Studi Kasus Perusahaan Yang Terdaftar Di Jakarta Islamic Index (Jii) Periode 2014-2018). 